\title{
The sealing ability of MTA apical plugs exposed to a phosphate-buffered saline
}

\begin{abstract}
Josiane de ALMEIDA ${ }^{1}$, Ana Maria Hecke ALVES ${ }^{2}$, Roberto Ferreira de MELO ${ }^{3}$, Mara Cristina Santos FELIPPE${ }^{2}$, Eduardo Antunes BORTOLUZZI², Cleonice da Silveira TEIXEIRA², Wilson Tadeu FELIPPE²
\end{abstract}

\begin{abstract}
1- DDS, MSc, PhD student in Endodontics, Department of Endodontics, School of Dentistry, Federal University of Santa Catarina, Florianópolis, SC, Brazil. 2- DDS, MSc, PhD, Associate Professor of Endodontics, Department of Endodontics, School of Dentistry, Federal University of Santa Catarina, Florianópolis, $\mathrm{SC}$, Brazil.

3- PharmD, MSc, PhD, Associate Professor of Clinical Analisys, Department of Clinical Analisys, School of Pharmacy, Federal University of Santa Catarina, Florianópolis, SC, Brazil.
\end{abstract}

Corresponding address: Josiane de Almeida - Rua Madre Maria Villac, 76 - apto 402 - Canasvieiras - Florianópolis - SC - Brazil - $88054-000$ - Phone: + 55 (0) 4837219549 - e-mail: dealmeidajosiane@hotmail.com

Submitted: January 11, 2013 - Modification: March 5, 2013 - Accepted: June 20, 2013

\section{ABSTRACT}

\begin{abstract}
$\mathrm{O}$ bjective: The aim of this study was to evaluate the influence of exposure of the mineral trioxide aggregate (MTA) - with and without calcium chloride $\left(\mathrm{CaCl}_{2}\right)$ - to phosphatebuffered saline (PBS) on the apical microleakage using a glucose leakage system. Material and Methods: Sixty root segments were randomly divided into 4 experimental groups $(n=15)$. After resecting the apical segments and enlarging the canals with Gates-Glidden drills, the apical cavities were filled with MTA with or without $\mathrm{CaCl}_{2}$ and the root canals were dressed with a moistened cotton pellet or PBS, as follows: 1) MTA/cotton pellet; 2) MTA/PBS; 3) $\mathrm{MTA}+10 \% \mathrm{CaCl}_{2} /$ cotton pellet; 4) $\mathrm{MTA}+10 \% \mathrm{CaCl}_{2} / \mathrm{PBS}$. All root segments were introduced in floral foams moistened with PBS. After 2 months, all root segments were prepared to evaluate the glucose leakage along the apical plugs. The amount of glucose leakage was measured following an enzymatic reaction and quantified by a spectrophotometer. Four roots were used as controls. The data were analyzed using Kruskal-Wallis and Mann-Whitney tests $(p<0.05)$. Results: There were no differences between groups 1 and $2(p>0.05)$, and 3 and $4(p>0.05)$. The addition of $\mathrm{CaCl}_{2}$ to the MTA significantly decreased its sealing ability $(p<0.05)$. Conclusion: The interaction with PBS did not improve the MTA sealing ability. The addition of $\mathrm{CaCl}_{2}$ to the MTA negatively influenced the apical seal.
\end{abstract}

Key words: Sealing ability. Apexification. Glucose.

\section{INTRODUCTION}

Most endodontic failures result from the passage of irritating substances from infected root canals to the periapical tissues ${ }^{24}$. Thus, any material used to seal communications between root canal and periodontium should offer an effective marginal seal7,11-13,15,21.

The sealing ability of mineral trioxide aggregate (MTA $)^{7,11-13,15,21}$ is superior to other materials ${ }^{5,11}$. Notwithstanding, few studies demonstrate total sealing efficiency when MTA is used as a retrograde filling material or as an apical plug 1,20.

The interaction of MTA with phosphate-buffered saline (PBS) positively influences its sealing ability ${ }^{15,16}$. In PBS, the MTA releases some components, triggering the formation of carbonated apatite. This spontaneous precipitation promotes a biomineralization process that leads to the formation of an interfacial layer with tag-like structures at the cement-dentin interface ${ }^{18}$.

It has been demonstrated that the addition of calcium chloride $\left(\mathrm{CaCl}_{2}\right)$ to MTA may improve its sealing ability ${ }^{2}$. It may also positively influence the biomineralization process since it promotes a great release of calcium ions and contributes to carbonated apatite formation at the cement-dentin interface ${ }^{18}$.

Therefore, the purpose of this study was to evaluate the influence of exposure of the MTA - with and without $\mathrm{CaCl}_{2}$ - to PBS on the apical microleakage using a glucose leakage system. 


\section{MATERIAL AND METHODS}

Sixty-four extracted, human, single-rooted teeth were used. The study was approved by the Ethics Committee for Research with Human Beings of the Federal University of Santa Catarina (protocol number 2128).

The procedures were performed as described by Reyes-Carmona, et al. ${ }^{19}$ (2010). The crowns were sectioned, and a $2 \mathrm{~mm}$ root tip resection was performed with a high-speed bur under cooling water, so that all root segments were about $12 \mathrm{~mm}$ long. The canals were cleaned and shaped using \#1-5 Gates-Glidden drills in a crown-down fashion, and $1 \%$ sodium hypochlorite $(\mathrm{NaOCl})$ was used for irrigation. A standardized open apex was created by retrograde preparation of the canal with a \#6 Gates-Glidden drill ( $\pm 1.50 \mathrm{~mm}$ diameter). The final canal rinse was performed with $17 \%$ EDTA followed by $1 \% \mathrm{NaOCl}$.

\section{Apexification procedures}

The root sections were randomly divided into 4 experimental groups $(n=15)$. Then, the apical cavities were filled and the root canals dressed as described in Figure 1.

MTA cement was mixed following the manufacturer's recommendations, and $\mathrm{MTA}+\mathrm{CaCl}_{2}$ was mixed according to Bortoluzzi, et al. ${ }^{2}$ (2009): $1 \mathrm{~g}$ of MTA with $0.1 \mathrm{~g}$ of $\mathrm{CaCl}_{2}$ mixed with $0.18 \mathrm{~mL}$ of $\mathrm{H}_{2} \mathrm{O}$.

The cement mixture was introduced into the canal, condensed with moistened paper points, and compacted with pluggers (Dentsply, Tulsa Dental, Tulsa, OK, USA) to create a $4 \mathrm{~mm}$ thick apical plug. Radiographs were taken from all root segments to ensure void-free MTA placement and plug thickness.

In groups 1 and 3 , a cotton pellet moistened with distilled water was placed in the cervical region of each root segment, which was replaced by a dry pellet after $24 \mathrm{~h}$. In groups 2 and 4 , the remaining canal space was filled with PBS (Dermus Farmácia Dermatológica e Coméstica Ltda, Florianópolis, SC, Brazil; $\mathrm{pH}=7.2$ ) as an intracanal dressing (Figure 1).

All access openings were covered with cotton pellets and filled with temporary cement (Cimpat, Septodont Brasil Ltda, São Paulo, SP, Brazil). Thereafter, the root segments were introduced in plastic vials containing floral foam moistened with $20 \mathrm{~mL}$ PBS and stored for 2 months at $37^{\circ} \mathrm{C}$.

\section{Assembled double chamber and glucose leakage measuring}

The root segments were fixed in a device designed to test glucose leakage [adapted from Leal, et al. ${ }^{13}$ (2011)]. The cervical portion of each root segment was fastened in a $2 \mathrm{~mL}$ Eppendorf tube with the apical $7 \mathrm{~mm}$ protruding through the end. The upper portion of the Eppendorf tube was connected to a screw device through which $0.75 \mathrm{~mL}$ of $1 \mathrm{~mol} \mathrm{~L}^{-1}$ of glucose solution was injected. The Eppendorf tube was attached to a bucket containing $0.75 \mathrm{~mL}$ of deionized water, so that the apical 3 $\mathrm{mm}$ of the root were immersed in the water. Lowviscosity cyanoacrylate adhesive (Araldite, Brascola, Joinville, SC, Brazil) was used to seal all interfaces and connections.

For the positive control group $(n=2)$, root segments without apical plugs were used. Two teeth with intact crowns, to which two layers of nail varnish were applied over the root surface, were used as negative control group $(n=2)$.

A pressure of $103 \mathrm{KPa}$ (15 psi) was created by a compressed air pump (Inalar Compact, NS Indústria de Aparelhos Médicos, São Paulo, SP, Brazil), which was connected to a system constituted by a manometer, a valve to control the pressure and a cannula in which the screw device, connected to the Eppendorf tube, was fixed. The glucose solution was forced into the tube for $60 \mathrm{~min}$. A system was developed to run six root segments simultaneously.

A $10 \mu \mathrm{L}$ aliquot of solution contained in the bucket (sample) was drawn using a micropipette, and traces of glucose were identified using a glucose kit (Glicose Pap Liquiform, Labtest Diagnóstica, Lagoa Santa, MG, Brazil).

Each sample was analyzed using a UV/VSI spectrophotometer (BIO-2000, Bioplus 2004R, Barueri, SP, Brazil) at $505 \mathrm{~nm}$ wavelength to obtain a specific optical density, and the values were converted to glucose concentration. All readings were taken in duplicate, and the mean value was considered for statistical analysis.

\section{Statistical analysis}

The Kruskal-Wallis test assessed overall differences between groups, represented by the mean values of glucose concentration. Since overall differences were observed, pairwise comparisons were performed using the Mann-Whitney $U$ test with a significance level of $5 \%$.

\begin{tabular}{|c|c|c|}
\hline Groups & Apical plug & Intracanal dressing \\
\hline 1 & $\mathrm{MTA}^{*}$ & Moistened cotton pellet \\
\hline 2 & $\mathrm{MTA}^{*}$ & PBS \\
\hline 3 & $\mathrm{MTA}^{*}+\mathrm{CaCl}_{2} \#$ & Moistened cotton pellet \\
\hline 4 & $\mathrm{MTA}^{*}+\mathrm{CaCl}_{2} \#$ & PBS \\
\hline
\end{tabular}

*MTA Branco - Angelus Soluções Odontológicas, Londrina, PR, Brazil

\# Vetec Química Fina, Rio de Janeiro, RJ, Brazil

Figure 1- Groups, materials used to form the apical plug and intracanal dressing 


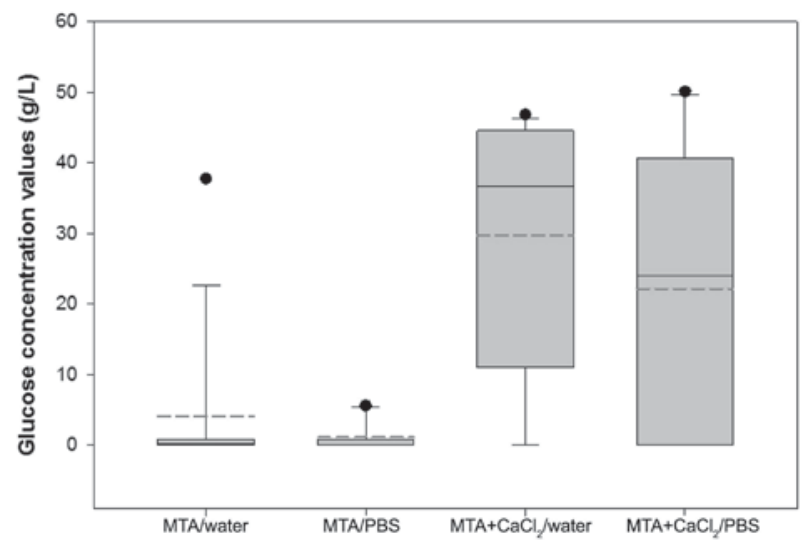

Figure 2- Box plots of the glucose concentration values in each group, illustrating the mean traces, minimal and maximal glucose traces and the median

Table 1- Groups, number and percentage of samples with traces of glucose solution and concentration mean value

\begin{tabular}{ccc}
\hline Groups & $\mathbf{n}(\%)$ & Glucose $\left(\mathbf{g ~ x ~ L}^{-1}\right)$ \\
\hline 1 (MTA/water) & $9(60)$ & 4.07 \\
2 (MTA/PBS) & $5(33.33)$ & 1.14 \\
$3\left(\mathrm{MTA}+\mathrm{CaCl}_{2} /\right.$ & $13(86.66)$ & 27.27 \\
$\quad$ water) & & \\
4 (MTA + $\mathrm{CaCl}_{2} /$ & $9(60)$ & 22.18 \\
PBS) & & \\
\hline
\end{tabular}

\section{RESULTS}

The graph in Figure 2 displays the mean, median and standard deviations and data distribution for each experimental group.

\section{Control groups}

In the negative control group no trace of glucose solution was detected, whereas in the positive control group the mean value of glucose concentration was $79 \mathrm{~g} \mathrm{x} \mathrm{L}^{-1}$.

\section{Experimental groups}

The number and percentage of samples that showed traces of solution, as well as the mean value of glucose concentration, are shown in Table 1. When the influence of interaction of the MTA with PBS as an intracanal dressing was evaluated, no difference was observed between the results of groups 1 and 2 ( $p>0.05)$, as well as between groups 3 and 4 ( $p>0.05)$. Nevertheless, the root segments that received PBS as an intracanal dressing showed the lowest number of samples with traces of the solution and the lower concentration mean value. When the influence of the addition of $\mathrm{CaCl}_{2}$ to MTA was analyzed, a significant difference was observed between the results of groups 1 and 3 $(p<0.05)$, as well as between the results of groups 2 and $4(p<0.05)$. The root segments that received $\mathrm{MTA}+\mathrm{CaCl}_{2}$ had a higher number of samples with traces of the solution and the higher mean glucose concentration.

\section{DISCUSSION}

This method is reliable, since it has a high degree of specificity and sensitivity ${ }^{27}$, overcoming most limitations observed in other leakage tests ${ }^{27}$; and it is useful for quantitative leakage evaluation ${ }^{13}$. Besides, it has already been proven that, until up to two hours of contact between MTA and glucose, there is no significant glucose reduction ${ }^{13}$.

Among the different groups, some root segments did not exhibit leakage. In teeth in which the apical plug was made with MTA, the sealing ability may be explained by a slight expansion that occurs after setting, which provides a better adaptation to the dentin walls 22,23 . As in all segments the external surface of the MTA contacted the PBS contained in the floral foam, it is likely that the biomineralization process in the apical third of the plugs ${ }^{19}$ additionally contributed to leakage reduction.

Conversely, some samples from the experimental groups presented glucose traces, that is, the plug allowed leakage. Other authors found that, though achieving superior results compared with other materials ${ }^{7}$, the sealing provided by MTA is not totally efficient ${ }^{16,28}$. The occurrence of leakage suggests the presence of through-and-through voids in the cement mass or in the cement-dentin interface ${ }^{13}$. The presence of interconnected pores in the material's body ${ }^{4}$ may also allow glucose leakage.

In this study, the segments that received PBS as intracanal dressing achieved better results. Other authors presented similar results when MTA was kept in contact with PBS ${ }^{15,16}$. Martin, et al. ${ }^{15}$ (2007) suggested that the continuous release of calcium and hydroxyl ions from MTA, and the later interaction with PBS, results in the deposition of carbonated apatite, which partially obliterates the spaces between MTA and the dentin, reducing the leakage. Besides, the formation of apatite on the external surface of the material contributes to the expansion of the cement ${ }^{9}$ and filling of the surface porosities ${ }^{10}$, improving the MTA adaptation to the canal walls. Reyes-Carmona, et al. ${ }^{19}$ (2010) showed that the use of PBS as intracanal dressing in association with the PBS that diffused through the apical barrier promotes the biomineralization process in MTA apical plugs. As the crystalline precipitates that are formed on the cement surface are porous ${ }^{25}$, studies are being conducted to determine whether the interaction of the MTA with PBS promotes changes in MTA porosity or not.

Contrasting previous studies ${ }^{3,12}$, the addition 
of $\mathrm{CaCl}_{2}$ to MTA reduced its sealing ability. When combined with $\mathrm{CaCl}_{2}$, MTA needs a smaller amount of water for mixture ${ }^{3}$, due to the hydration of the silicate ${ }^{17}$ and the hygroscopic action of $\mathrm{CaCl}_{2}{ }^{2}$. The immediate contact of $\mathrm{MTA}+\mathrm{CaCl}_{2}$ with PBS or moistened cotton may have promoted greater water absorption, which changed the powder-liquid proportion and increased its porosity ${ }^{8,14}$. Above the ideal proportion, water favors the formation of many capillary pores, increasing shrinkage and cracking, with consequent loss on the sealing ability ${ }^{14}$. It must be mentioned that Dreger, et al. ${ }^{6}$ (2012) observed lesser mineral deposition in tubes filled with Portland cement $+\mathrm{CaCl}_{2}$ than in those filled with Portland cement alone. According to the authors, the lower bioactivity was a result of addition of calcium chloride, which reduced the setting time of the cement and consequently reduced the dissolution of its components.

There were large discrepancies in the glucose concentration values when samples of a same group were compared. The high leakage values indicate the existence of wide through-and-through voids in the material, while lower values indicate the presence of a narrow through-and-through void ${ }^{26}$.

The use of PBS as intracanal dressing may improve MTA sealing. However, due to the controversies still found in microleakage studies, the results of this research must be validated by other methodologies such as the bacterial leakage test, currently in progress.

\section{CONCLUSION}

The interaction with PBS did not improve the MTA sealing ability. The addition of $\mathrm{CaCl}_{2}$ to the MTA negatively influenced the apical seal.

\section{ACKNOWLEDGEMENTS}

The authors would like to thank Angelus Soluções Odontológicas for kindly providing the MTA for this study. The authors deny any potential conflict of interests.

\section{REFERENCES}

1- Aqrabawi, J. Sealing ability of amalgam, super EBA cement, and MTA when used as retrograde filling materials. Brit Dent $\mathrm{J}$. 2000; $188: 266-8$.

2- Bortoluzzi EA, Broon NJ, Bramante CM, Felippe WT, Tanomaru Filho M, Esberard RM. The influence of calcium chloride on the setting time, solubility, disintegration, and $\mathrm{pH}$ of mineral trioxide aggregate and white Portland cement with a radiopacifier. J Endod. 2009;35:550-4.

3- Bortoluzzi EA, Broon NJ, Bramante CM, Garcia RB, Moraes IG, Bernardineli N. Sealing ability of MTA and radiopaque Portland cement with or without calcium chloride for root-end filling. J Endod. 2006;32:897-900.
4- Camilleri J, Mallia B. Evaluation of the dimensional changes of mineral trioxide aggregate sealer. Int Endod J. 2011;44:416-24. 5- De Bruyne MAA, De Bruyne RJE, De Moor RJG. Capillary flow porometry to assess the seal provided by root-end filling materials in a standardized and reproducible way. J Endod. 2006;32:206-9. 6- Dreger LAS, Felippe WT, Reyes-Carmona JF, Felippe GS, Bortoluzzi EA, Felippe MCS. Mineral trioxide aggregate and Portland cement promote biomineralization in vivo. J Endod. 2012;38:324-9.

7- Ferk Luketić SF, Malcić A, Jukić S, Anić I, Šegović S, Kalenić S. Coronal microleakage of two root-end filling materials using a polymicrobial marker. J Endod. 2008;34:201-3.

8- Fridland M, Rosado R. Mineral trioxide aggregate (MTA) solubility and porosity with different water-to-powder ratios. J Endod. 2003;29:814-7.

9- Gandolfi MG, Taddei P, Tinti A, De Stefano Dorigo E, Rossi PL, Prati C. Kinetics of apatite formation on a calcium-silicate cement for root-end filling during ageing in physiological-like phosphate solutions. Clin Oral Invest. 2009;14:659-68.

10- Gandolfi MG, Taddei P, Tinti A, Prati C. Apatite-forming ability (bioactivity) of ProRoot MTA. Int Endod J. 2010;43:917-29.

11- Gondim E Jr, Kim S, Souza-Filho FJ. An investigation of microleakage from root-end fillings in ultrasonic retrograde cavities with or without finishing: a quantitative analysis. Oral Surg Oral Med Oral Pathol Oral Radiol Endod. 2005;99:755-60.

12- Hong ST, Bae KS, Baek SH, Kum KY, Lee W. Microleakage of accelerated mineral trioxide aggregate and Portland cement in an in vitro apexification model. J Endod. 2008;34:56-8.

13- Leal F, De-Deus G, Brandão C, Luna AS, Fidel SR, Souza EM. Comparison of the root-end seal provided by bioceramic repair cements and White MTA. Int Endod J. 2011;44:662-8.

14- Manual técnico: aditivos para congreto e argamassas. $39^{\text {th }}$ ed. Salvador: Vedacit; 2003.

15- Martin RL, Monticcelli F, Bracket WW, Loushine RJ, Rockman RA, Ferrari $M$, et al. Sealing properties of mineral trioxide aggregate orthograde apical plugs and root fillings in an in vitro apexification model. J Endod. 2007;33:272-5.

16- Parirokh M, Askarifard S, Mansouri S, Haghdoost AA, Raoof $M$, Torabinejad $M$. Effect of phosphate buffer saline on coronal leakage of mineral trioxide aggregate. J Oral Sci. 2009;51:187-91. 17- Ramachandran VS. Concrete admixtures handbook. New Jersey: Noyes Publications; 1984.

18- Reyes-Carmona JF, Felippe MS, Felippe WT. Biomineralization ability and interaction of mineral trioxide aggregate and white portland cement with dentin in a phosphate-containing fluid. J Endod. 2009;35:731-6.

19- Reyes-Carmona JF, Felippe MS, Felippe WT. A phosphatebuffered saline intracanal dressing improves the biomineralization ability of mineral trioxide aggregate apical plugs. J Endod. 2010;36:1648-52.

20- Scheerer SQ, Steiman HR, Cohen J. A comparative evaluation of three root-end filling materials: an in vitro leakage study using Prevotella nigrescens. J Endod. 2001;27:40-2.

21- Shahi S, Rahimi S, Hasan M, Shiezadeh V, Abdolrahimi M. Sealing ability of mineral trioxide aggregate and Portland cement for furcal perforation repair: a protein leakage study. J Oral Sci. 2009;51:601-6.

22- Sluyk SR, Moon PC, Hartwell GR. Evaluation of setting properties and retention characteristics of mineral trioxide aggregate when used as a furcation perforation repair material. J Endod. 1998;24:768-71.

23- Storm B, Eichmiller FC, Tordik PA, Goodell GG. Setting expansion of gray and white mineral trioxide aggregate and Portland cement. J Endod. 2008;34:80-2.

24- Torabinejad M, Parirokh M. Mineral trioxide aggregate: a comprehensive literature review-part II: leakage and biocompatibility investigations. J Endod. 2010;36:190-202. 
25- Weller RN, Tay KCY, Garret LV, Mai S, Primus CM, Gutmann $\mathrm{JL}$, et al. Microscopic appearance and apical seal of root canals filled with gutta-percha and ProRoot Endo Sealer after immersion in a phosphate-containing fluid. Int Endod J. 2008;41:977-86.

26- Wu MK, van der Sluis LW, Ardila CN, Wesselink PR. Fluid movement along the coronal two-thirds of root fillings placed by three different gutta-percha techniques. Int Endod J. 2003;36:533-40.
27- Xu Q, Fan MW, Fan B, Cheung GSP, Hu HL. A new quantitative method using glucose for analysis of endodontic leakage. Oral Surg Oral Med Oral Pathol Oral Radiol Endod. 2005;99:107-11. 28- Yildirim T, Er K, Taşdemir T, Tahan E, Buruk K, Serper A. Effect of smear layer and root-end cavity thickness on apical sealing ability of MTA as a root-end filling material: a bacterial leakage study. Oral Surg Oral Med Oral Pathol Oral Radiol Endod. 2010;109:e67-72. 